Acta Poetica $26(1-2)$

PRIMAVERA-OTOÑO

2005

\title{
La adivinanza. Sentido y pervivencia
}

\author{
María Teresa Miaja de la Peña
}

La adivinanza como forma poética ocupa un lugar importante en la tradición lírica de todas las culturas desde tiempos remotos, gracias a su capacidad de transformarse, adaptarse y arraigarse en el gusto popular. En ella se conjuntan el ingenio y la poesía en un juego verbal que disfrutan tanto los niños como los adultos. Juego verbal que se nutre de múltiples recursos retóricos, léxicos y métricos para construir, dentro de una estructura aparentemente sencilla, un universo de enigmas y retos a la imaginación.

For centuries riddles have been part of lyric tradition in most cultures. They can easily adapt to popular taste. Riddles bring together both imagination and poetry in a mental game based on rhetorical figures, as well as lexical and metrical resources. Verbal games, enclosed in an apparently simple self contained structure, imply a mental challenge. 
Acta Poetica $26(1-2)$

PRIMAVERA-OTOÑO

2005

María Teresa Miaja de la Peña

Facultad de Filosofía y Letras, UNAM

\title{
La adivinanza. Sentido y pervivencia
}

\author{
A Pedro C. Cerrillo, amigo y colega, por haberme \\ guiado al reencuentro de estos maravillosos espa- \\ cios líricos. \\ "L'art est fait pour troubler" \\ Braque
}

La adivinanza, añeja en sus orígenes, por su estructura y función se va adaptando a las distintas circunstancias culturales, sociales, históricas, generando nuevas versiones de una tradición tan arraigada en el sentir popular como lo es esta forma lírica de comunicación del saber y entretener. Ingenio y poesía unidos en un juego mental y verbal que ha perdurado por siglos haciendo las delicias de niños y adultos.

Esta forma poética suele basarse para su construcción en elementos de la poesía tradicional popular como son los versos de arte menor, las cuartetas octosilábicas de rima asonante o consonante cruzada, el uso de la forma paralelística, del símil, la metáfora, la metonimia, la alegoría, la dilogía, la analogía y el desglose lingüístico entre otros. 


\section{Géneros colindantes y antecedentes}

El afán de revelar lo oculto ha estado presente en la historia de la humanidad desde siempre y de ello existen valiosos y variados ejemplos literarios en obras como la Biblia, La epopeya de Gilgamesh, el Libro de Apolonio, Las mil y una noches, además de los recogidos en la tradición griega, latina, celta, germana, asiria, egipcia, india, china, náhuatl, maya, quiché, entre otras muchas. Para tratar de entender lo oculto, descifrarlo, conjurarlo o resolverlo el hombre se ha valido de toda suerte de artilugios adivinatorios. Se trata de entender lo "divino", del divinare, addivinare latino, como lo secreto, lo ignorado, y de adivinar, como un don divino que permite trascender lo humano, lo terreno. De ahí que la búsqueda de una explicación a través de mitos, ritos y artes adivinatorias sea tan ancestral como el hombre mismo. Las formas más difundidas para realizar esa búsqueda han sido sin duda el oráculo, las profecías, el enigma, el acertijo, la adivinanza.

En este trabajo, nos ocuparemos de la adivinanza en un intento de entender qué es, en qué consiste, cuál es su función y cómo ha sido su permanencia y trascendencia a través del tiempo y el espacio, en particular de las adivinanzas que conocemos actualmente en México. Sabemos que existen adivinanzas en todas las culturas y las ha habido en todos los tiempos, sin embargo, aquí nos centraremos en las de tradición popular que se dan en nuestro país que son resultado de la mezcla de la tradición española y la indígena. ${ }^{1}$

\section{Definición}

Según José Luis Gárfer y Concha Fernández, especialistas reconocidos en este género, "Primero fue el acertijo y, cuando

\footnotetext{
${ }^{1}$ Las adivinanzas cultas siguen distintos parámetros pues suelen ser de mayor extensión estrófica, se expresan con un léxico más elaborado y tratan temas de índole más sofisticada y compleja.
} 
éste se arropó con el verso, nació la adivinanza, una pequeña y valiosa joya poética de nuestra literatura popular" (Gárfer y Fernández 1994, vii). ${ }^{2}$ Ambos géneros coinciden en plantear una pregunta ingeniosa, sin embargo en tanto que el acertijo lo hace en prosa, la adivinanza lo hace en verso, y ésta, además, dentro de una estructura más compleja, y elaborada con parámetros más definidos en su construcción, como el uso de lenguaje simbólico y rimado con el que logra conformar "un rodeo de palabras, una descripción metafórica" (Gárfer y Fernández 1993, 11), donde se esconde la clave a resolver.

La adivinanza de tipo popular y tradicional ha sido definida de múltiples maneras. Para algunos su esencia está en el hecho de ser un ejercicio intelectual, un juego en el que se reta a un contrario de forma ingeniosa para que resuelva un breve enigma o problema, para el cual puede o no incluirse una clave, a veces verdadera, otras, falsa o encubierta.

$\mathrm{Al}$ respecto María Gabriela González considera que la adivinanza:

Es uno de los primeros y más difundidos tipos de pensamiento formulado; es el resultado del proceso primario de asociación mental, de la comparación y la percepción de parecidos y diferencias aunados al humor y al ingenio. La sorpresa al descubrir similitud entre objetos, en los que de ordinario no se esperaría encontrarla, es un elemento básico para su elaboración: sin sorpresa no hay adivinanza. $(1999,21)$

\section{Características}

\section{Capacidad dialógica}

La adivinanza es ante todo una comunicación entre dos sujetos: el que emite el reto (enunciador) y al que éste va destina-

\footnotetext{
2 José Luis Gárfer y Concha Fernández fueron quienes acuñaron el adecuado término de "adivinancero", en 1983, para las colecciones de adivinanzas, siguiendo la tradición de términos como cancionero, refranero, romancero, etc.
} 
do (destinatario). Entre ambos se establece un juego dialógico que se convierte en un desafío de saber. El enunciador es el que domina y dirige el reto, en tanto que el destinatario lo juega, lo adivina. El enunciador plantea la adivinanza y conoce la respuesta; pide al destinatario un ejercicio de imaginación, de concentración y de desentrañamiento, con lo que queda establecido el juego intelectual, mismo que suele ser cerrado entre el emisor y el receptor. Este último puede ser único o colectivo. El hecho de que sea cerrado, entre un yo y un tú, hace que se tienda a un uso frecuente de pronombres (personales, posesivos), desinencias verbales de primera y segunda persona del singular y del plural, apelativos, y cualquier otro elemento que connote individualización del emisario y/o del destinatario. Así, tenemos al que plantea el reto, como dueño del saber y la respuesta, frente a un "tú", a quien se le inquiere directamente, como si el primero lo tuviese ante sí y pudiese observarlo y decirle: "mírame"; "Soy chiquito..."; "Tengo brazos y no tengo...", o como si ese "tú" fuera un sujeto universal: "adivina, adivinador", interpelado como cómplice y conocedor del ritual propuesto, capaz de dilucidar la respuesta por pertenecer a la misma comunidad o estrato del primero. Sería inútil que se planteara el juego ante quien no participa por falta de capacidad o de voluntad o de deseo de ser retado, pues la cadena dialógica quedaría trunca.

\section{Estructura}

En la adivinanza es importante la estructura, pues en un breve espacio se debe incluir una serie de elementos que la conforman como una fórmula concebida para ser contada, y que cumplen una función primordial en la transmisión del mensaje. La organización de dichos elementos hace posible identificar al género y conocer en forma precisa las reglas a seguir en el juego. Lo anterior debido a que por una parte éstos tienen 
que ver con las características propias del género lírico, y por otra con su función lúdica.

En este sentido Gárfer y Fernández afirman que,

Si se estudia en profundidad la estructura de las adivinanzas populares, es fácil llegar a fórmulas fiables para su elaboración, partiendo básicamente de la metáfora, alegoría, greguería, abundante adjetivación, perífrasis léxicas, otros sofisticados ingredientes y muy fácilmente a través del reiterado carácter formulístico de la adivinanza popular. $(1993,12)$

Básicamente estos elementos son los siguientes: fórmulas de introducción, elementos orientadores, elementos desorientadores, fórmulas de conclusión. El primero y el último suelen estar presentes en la adivinanza, pero si son omitidos por el emisor, el receptor los da por sentados, pues son parte implícita del texto. En el caso de los segundos y terceros, el orden puede ser alterado como parte del juego, sin que la modificación afecte su sentido.

A) Fórmulas de introducción

Suelen aparecer únicamente en el caso de versos pareados y tienen los siguientes propósitos:

a) provocar con un reto: "adivina, adivinanza", "adivina, buen adivinador", "adivina adivinador, adivina";

b) provocar con una pregunta: "¿qué cosa y cosa...?", “¿qué cosa será la cosa...?”, "maravilla, maravilla, ¿qué será?”, ¿cuál es aquel...?

c) ubicar espacialmente: "En el monte fui nacido...", "En casa de Chi...";

d) describir una característica como clave inicial: "Blanco fue mi nacimiento...", "Oro no es...", "Te la digo y no me entiendes...".

${ }^{3}$ Ésta suele ser la fórmula propia de los zazaniles: "Zazan ¿tleino?”, que fue traducida por fray Bernardino de Sahagún como "¿Qué cosa y cosa?”. 
B) Fórmulas de conclusión

Al cierre de la adivinanza se sugiere lo fácil o difícil del reto, se anima o desanima para que continúe el juego, e incluso se hace burla o se ofrece recompensa por el éxito en el resultado.

a) fácil: "por ser la letra tan clara", "quiero que me la adivines", "ya ves, cuán claro es", "adivíname lo que es";

b) difícil: "no me lo adivinas hoy", "ni me lo adivinarás mañana";

c) ánimo: "adivina, adivinador, ¿quién es ese gran señor?", "Si quieres que te la diga, espera...";

d) burla: "el que no lo adivine es un gran borricón";

e) reto: "adivíname, si eres hombre", "si eres listo adivinarás", "adivínalo si puedes";

f) recompensa: "el que me lo adivine, comerá pan y tortilla".

C) Elementos orientadores

Suelen estar dentro del mismo texto, generalmente mediante la descomposición de la palabra — por fragmentación o desglose - construyendo así una especie de etimologías populares, que crean un cambio semántico pertinente para el juego.

Agua pasa por mi casa, cate de mi corazón.

(el aguacate)

En casa de $\underline{\mathrm{Chi}}$

mataron a $\underline{\mathrm{Ri}}$.

vino $\underline{\mathrm{Mo}}$

y dijo Ya.

(la chirimoya)

O incluyendo en el texto el elemento a buscar, que puede ser una letra o una palabra:

En medio de cielo estoy, sin ser lucero ni estrella.

(la letra e) 
Te la digo y no me entiendes,

te la vuelvo a repetir. (la tela)

Gracias a ello se orienta al receptor en su proceso de recreación de un universo imaginario en el que se encuentra la respuesta anhelada.

D) Elementos desorientadores

A través de ingeniosas trampas y argucias léxicas, retóricas o de sentido se suele desorientar al receptor para que se pierda en el camino y no encuentre la respuesta adecuada, ya sea porque a veces ésta es una broma o porque no implica una respuesta lógica.

Por ejemplo, en el caso de la siguiente adivinanza: "Lana sube, lana baja, ¿qué es?". La respuesta adecuada tiene que ser "la navaja", en la que el sentido esta desglosado dentro del texto, una de las formas de construcción más comunes. Sin embargo, otra respuesta puede ser "un borrego en un elevador", que también sería válida como símil. El emisor juega con ambas con el objeto de burlar al receptor y, para ridiculizarlo, elige como correcta la que éste no le dio.

Quizá el más común de los juegos como elemento desorientador es el de la dilogía o el doble sentido, especialmente si éste puede adquirir un tinte escatológico o sexual, lo cual resulta muy atractivo para los niños, y más aún para los adolescentes, quienes se divierten engañando con el reto cuya respuesta resulta ser más inocente y simple. En este caso el uso de la personificación, la animalización, la prosopopeya y el símil fungen como recursos frecuentes:

Entra lo duro en lo blando, quedan las bolas colgando. (los aretes)

Lo que importa finalmente es el juego, y éste consiste en descubrir la respuesta oculta, ya sea por engaño, por ingenio, 
por disfraz, por descomposición, por fragmentación o por desorientación.

\section{Métrica}

La adivinanza es pródiga en el uso de imágenes poéticas porque es, como hemos señalado, ante todo poesía. Gracias a ella la realidad cotidiana se transforma en algo distinto y a la vez oculto, que se construye mediante tropos, figuras retóricas, juegos de palabras y rimas que encubren el objeto a dilucidar, haciendo invisible lo que debiera ser visible.

Nada contribuye más a la conformación y a la pervivencia de la adivinanza que su esencia poética, ya que por ser verso es ante todo bella, además resulta de fácil memorización por ser rítmica, melódica, y, sobre todo, abierta y flexible, lo que la hace capaz de aceptar infinitas variaciones léxicas o temáticas.

En la adivinanza hay una gran riqueza métrica reflejada en características tales como: la presencia de estructuras simétricas, el predominio de la versificación irregular, la acentuación variable, la sucesión regular de periodos rítmicos, la ausencia de encabalgamientos, la diversidad de formas isosilábicas o heterosilábicas.

Los versos suelen ser octosilábicos, aunque hay hexasílabos y pentasílabos, y suelen hallarse en estrofas de dos a cuatro versos, las más comunes, pero pueden llegar a veces a seis u ocho. Esto último sucede más frecuentemente en el caso de las adivinanzas cultas que en las populares.

Se puede afirmar que las cuartetas octosilábicas de rima asonante o consonante cruzada, y el uso de la forma paralelística constituyen la forma más frecuente de nuestras adivinanzas. 


\section{Aspectos lingüísticos}

A) Aspecto léxico

Por el carácter eminentemente oral de las adivinanzas desde sus orígenes, su léxico tiende a ser de dos tipos: el poético o el cotidiano. El primero lo encontramos en los textos en que los elementos orientadores o desorientadores se construyen a través de un lenguaje pleno de tropos o figuras retóricas tales como la anáfora, el símil, la metáfora, la metonimia, la alegoría, la onomatopeya, el calambur, o de recursos estilísticos como repeticiones (reduplicación, anadiplosis, paronomasia, sinonimia, etcétera) o la creación de nuevos lexemas.

En lo alto vive,

en lo alto mora,

en lo alto teje

la tejedora.

(la araña)

Arca cerrada

de buen parecer

no hay carpintero

que la sepa hacer.

(la nuez)

Quiero que me traigas

un mundo

y dentro del mundo

el mar.

(el coco)

Traca que traca,

tras la petaca.

(el ratón)

Nico, Nico y su mujer

tiene cola, pies y pico, y los hijos de Nico, Nico, ni cola, ni pies, ni pico.

(la gallina y los huevos) 
El segundo, en los textos donde el referente alude a aquello que forma parte de la realidad del receptor, y que por ende le es tan cercano y familiar que se le ha de ocultar mediante diversos recursos: desglosándolo semánticamente, personificándolo, describiéndolo, o incluso deconstruyéndolo, con lo que se va llevando de la mano al receptor, ofreciéndole elementos que le son familiares, hacia el camino de la respuesta anhelada.

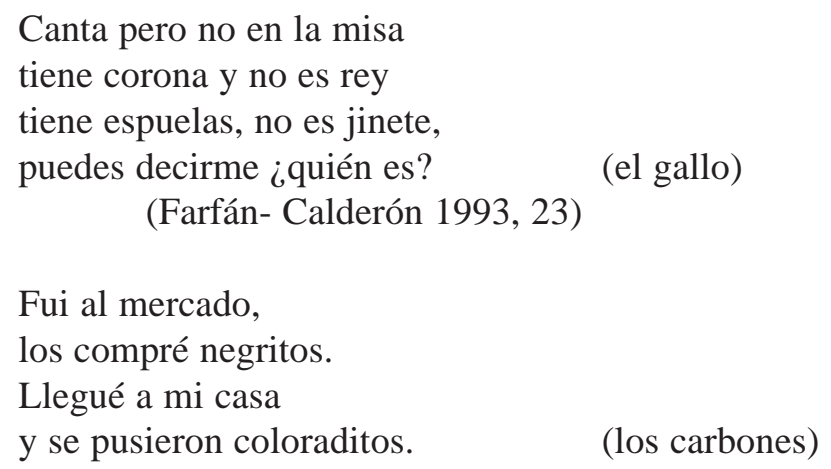

Fui al mercado, los compré negritos.

Llegué a mi casa

y se pusieron coloraditos. (los carbones)

El léxico utilizado en la adivinanza es en ambos casos el mismo pero requiere de dos niveles distintos de decodificación: uno que remite a una reflexión e interpretación sobre lo construido con la imagen o el tropo, y otro que implica un conocimiento de la realidad circundante y cotidiana. Con las palabras se juega, ellas son en sí la materia prima del juego, de ahí que los sustantivos comunes o propios, los adjetivos, los verbos, e incluso los grupos léxicos puedan fungir como sustitutivos o innovadores, creando con ello nuevos significados y connotaciones.

B) Aspecto sintáctico

En las adivinanzas se trastoca tanto el sentido como el orden sintáctico, más aún cuando en este juego del lenguaje la secuencia puede contribuir a develar el objeto. De ahí la presen- 
cia de asociaciones comparativas o adversativas, con las que se contraponen verbos, pronombres, sustantivos, adverbios o adjetivos tanto en su significado como en su posición sintáctica en el texto.

Tranco barranco

mechones blancos.

(el avestruz)

Canta sin voz,

vuela sin alas,

sin dientes muerde,

sin boca habla.

(el viento)

\section{C) Semántico}

En la composición de la adivinanza observamos un gusto por el uso de estructuras acumulativas que ayudan a la construcción del objeto referido y del ritmo. Esto puede lograrse, según Cerrillo (2000, 46-47), de tres maneras: por encadenamiento, por enumeración, por adición.

En el primer caso, por encadenamiento, se unen el último elemento de una proposición con el primero de la siguiente mediante el uso de conjunciones, preposiciones, comas, o incluso por elipsis.

Casquete, sobre casquete, casquete de paño fino, no lo aciertas en un año,

ni en dos, si yo no lo digo. (la cebolla)

por enumeración, cuando se suman una serie de elementos que pueden ser orientadores o no:

Soy una señora muy aseñorada, con muchas enaguas sin una puntada, aunque muchas tengo a cual más mejor, siempre llevo encima la más sucia y peor. (la cebolla) 
y por adición, cuando se suman elementos de un mismo paradigma:

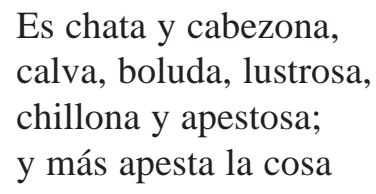

En estas adivinanzas la cebolla se asocia primero con un "paño fino", luego se personifica como "señora muy aseñorada, con muchas enaguas sin una puntada" y finalmente, utilizando un registro más coloquial y grotesco, se describe como "chata y cabezona, calva, boluda, lustrosa, chillona y apestosa". En los tres casos se conservan ciertos rasgos que permiten identificarla como cebolla. Lo que muestra la creación de nuevas connotaciones acerca de un referente, ampliando así sus campos significativos a través del uso de metáforas, analogías, juegos de palabras, y conformando un ritmo y entonación propios de la poesía. Según Celaya es a través de la palabra "jugada" como la adivinanza puede "devolvernos ese sentido del lenguaje en trance de desaparecer bajo la petrificación lógica y la significación convencional" (Cerrillo 2000, 47).

\section{Temática}

Pocos géneros literarios pueden vanagloriarse de ser tan variados y abarcadores en cuanto a temática se refiere como la adivinanza, quizá ninguno logre acercarse a sus posibilidades pues en ella se puede referir todo, tanto lo real como lo imaginario, lo cotidiano y lo ocasional, lo visible y lo invisible.

En un reciente libro sobre adivinanzas Regino Etxabe maneja los temas con títulos tan sugerentes como: "El arca de Noé" (para los animales); "El ejército del bosque" (para las 
plantas); "De carne y hueso" (para las partes del cuerpo); "El guardarropa" (para la ropa); "Hogar dulce hogar" (para los objetos domésticos); "A mesa puesta" (para la comida y los utensilios); "Un paseo por las nubes" (para los planetas, estrellas y elementos); "La vuelta al mundo en 28 adivinanzas" (para el ecosistema); "Sopa de letras" (para las letras); "El tiempo es oro" (para lo cronológico); "Damas y caballeros" (para las personas); "Conceptos intocables" (para los conceptos); "El desván" (para los objetos); "Algunos problemas sin resolver" (para los problemas matemáticos o lógicos). De esta ingeniosa manera el autor nos introduce al mundo de las adivinanzas abriendo múltiples puertas y cajones que prometen ser divertidos por su forma de enunciarlos (Etxabe 2004, 169).

Todo lo cual puede resumirse en grandes apartados genéricos que abarcan: lo abstracto, el hombre (las personas, el cuerpo, las relaciones con otros, los oficios); la naturaleza (los animales, las plantas, el espacio); los objetos (los domésticos, la vestimenta, los alimentos, el transporte, los utensilios, los instrumentos musicales); los juegos, la escritura (los números, las letras), la historia, la religión, en fin, todo lo nombrable y lo innombrable, lo que nos rodea física y mentalmente.

Al respecto Antonio Salgado comenta: "como vemos, las adivinanzas tienen la gran cualidad de la sencillez para tratar los temas más disímbolos, sin que ello signifique ni deterioro de conciencia ni ostentación de suficiencia" (1990, 7). Simplemente reflejan el universo en su totalidad, el real y el imaginario, y lo convierten en poesía.

\section{Clasificación}

Es una tarea difícil la de tratar de catalogar las adivinanzas dada su diversidad temática, pues todos los intentos parecen ser siempre arbitrarios y, por lo mismo, poco precisos. Las clasificaciones más frecuentes de los textos se hacen: por orden al- 
fabético, lo que facilita su localización pero oculta el sentido y relación entre ellos; por materia, lo que los asocia semánticamente, pero los separa de aquellos con los que comparten elementos de construcción o de estructura; por temas, lo que los conjunta por el asunto de que se ocupan, pero los hace perder su vínculo léxico; por su estructura, lo que los disocia de su sentido connotativo; por analogía, lo que los reúne por campo semántico, pero los aleja del conjunto genérico.

Otra posibilidad es la de clasificar las adivinanzas de acuerdo a sus componentes linguiísticos (fonéticos, sintácticos, semánticos) esto podría ser muy útil en un estudio especializado pero dificulta el acceso de los lectores al material.

Así vemos que cualquier camino por el que se opte tiene su posibilidad de acercamiento a la vez que deja un aspecto por atender, sin embargo tan válido puede ser uno como otro y lo que importa es dar un orden al corpus con que se cuenta.

\section{Función}

\section{Según Gabriela González Gutiérrez:}

La adivinanza nos enseña, por ensayo y error, a probar nuestro propio proceso de asociaciones. Nos enseña a ver, a conocer de una manera distinta, apelando a, por lo menos, cuatro niveles de comprensión: el intelectivo o lógico, el estético o sensorial, el didáctico y el lúdico o emotivo. $(1999,37)$

Aquí sólo retomo tres de estos aspectos: el lúdico, el estético y el didáctico, ya que el intelectivo o lógico queda implícito como proceso mental para llegar a la solución o respuesta.

\section{A) Función lúdica}

Nadie puede negar el carácter lúdico de la adivinanza pues ésta es ante todo un juego, un pasatiempo que consiste en armar rompecabezas verbales para poder apreciar la imagen buscada. 
Para lograrlo es necesario concentrarse en varios de sus elementos, escuchar cuidadosamente las palabras y analizar cada verso, pues la respuesta puede estar escondida en algunas de las sílabas iniciales o finales, o también en palabras clave que describen el objeto, ya sea en forma real o velada a través de una metáfora por ejemplo.

Gracias a su carácter lúdico y mnemotécnico la adivinanza ha podido crecer y enriquecerse en ámbitos tan diversos como el urbano, el rural, el doméstico, el comunitario, el escolar, el de la plaza y el de la calle, e incluso el impreso y el de los medios. Su sola limitante es la imaginación, en tanto uno puede crear y recrear adivinanzas sobre cualquier asunto, tema, objeto, actividad, elemento, ente o idea con que desee retar o provocar a su oponente. Las reglas del juego son claras y precisas, siguen una lógica y una estructura, se adornan con la poesía y, simplemente, surgen ante un receptor individual o universal para despertar en él el gozo de la fantasía, de la intriga por el saber, el encuentro con el misterio y el afán de descubrir.

\section{B) Función estética-poética}

La adivinanza sensibiliza a los niños y jóvenes con la poesía, fomenta en ellos el gusto por la palabra, el ritmo y la versificación, además de que los familiariza con imágenes abstractas, creadas a partir de tropos y figuras retóricas que adquieren forma en su imaginación y les despiertan nuevas y maravillosas maneras de ver el mundo. No es lo mismo pensar en el cielo y las estrellas como conceptos concretos que descubrirlas a través de un texto como éste:

Siempre quietas, siempre inquietas, de día dormidas, de noche despiertas. (las estrellas) 
O en la también bella versión de tradición náhuatl recogida por Fray Bernardino de Sahagún en su Historia general de las cosas de la Nueva España:

¿Qué cosa y cosa una jícara azul sembrada de maíces tostados que se llaman momóchitl? Éste es el cielo, que está sembrado de estrellas. (Sahagún 2000, 669) ${ }^{4}$

Antonio Alatorre en su estudio "De folklore infantil" afirma que los niños se sienten seducidos por la rima, "lo que pasa es que algunos la olvidan al hacerse adultos. El amor a la rima indica que los niños tienen muy fresca, muy reciente, la experiencia del lenguaje" (1973, 45). Es precisamente en este gusto por el lenguaje en donde la adivinanza encuentra su espacio de solaz, como bien lo dice el autor refiriéndose al libro de José Moreno Villa, Lo que sabía mi loro, "en él metió su infancia. O por lo menos esa parte de la infancia que va asociada con la risa y la sonrisa, con el ritmo, con el juego -y con el juego más emocionante de todos: el lenguaje" $(1973,35)$.

C) Función didáctica

Como afirma Antonio Salgado: "la adivinanza es la caja de sorpresas que enseña al niño a desentrañar problemas mayores" $(1998,9)$, pues gracias a su capacidad dialógica, analógica, semántica, mnemotécnica, estructural y métrica los niños captan y comprenden un código lingüístico que les comunica un mensaje en forma precisa pero, y sobre todo, de juego. Y así, jugando, memorizando, pensando y observando con atención los sonidos y su sentido, los niños y jóvenes aprenden a

\footnotetext{
${ }^{4}$ Sobre los zazaniles, adivinanzas de tradición indígena, he escrito en varios momentos y ahí he hecho referencia a los magníficos estudios de Gisela Beutler (1979), Virginia Rodríguez Rivera (1943), Jonathan D. Amith (1997) y Patrick Johansson (2004).
} 
asociar unos con otros y con ello a descubrir la respuesta deseada. En este sentido las adivinanzas cumplen una importante función en la formación intelectual de los niños y jóvenes pues fomentan en ellos la capacidad de razonar en forma lógica, de descubrir y desentrañar el mensaje oculto dentro de una "expresión criptomórfica" (Gárfer y Fernández 1983, 22). Al tiempo que encuentran la respuesta buscada, aprenden a afrontar "lo capcioso, esa caja de sorpresas que tiene como premio el poder desarrollar en la vida adulta los trabajos elaborados, las ciencias exactas, los cálculos científicos y todo aquello que tenga que ser desentrañado mediante la imaginación, agotando todos los recursos mentales posibles"(Salgado 1988, 7). También Belén Bermejo Meléndez afirma que:

el placer que vemos en la sonrisa de un niño cuando adivina en qué mano guardamos un caramelo es la misma satisfacción del científico que descubre una vacuna o del arqueólogo que encuentra una vasija del siglo III. La permanencia y vigencia de la adivinanza se debe precisamente a esto: a su especialísima construcción y a la necesidad del hombre de descubrir lo que se halla oculto. $(2000,7)$

Por ello no debemos circunscribir la adivinanza únicamente al mundo infantil y juvenil, pues aunque este género suele aprenderse en estas etapas de la vida, generalmente se conserva a lo largo de ella. Afirma Pedro C. Cerrillo que las adivinanzas "no son exclusivas del mundo infantil, sino que pertenecen al patrimonio folklórico general" (1989, 469). Todos sabemos y recordamos adivinanzas ya que suelen acompañarnos y deleitarnos al igual que otras formas poéticas de tradición popular, de ahí que cuando alguien menciona una, de inmediato pensamos en otra que se le asocia, retomando con ello el juego eterno del reto y la búsqueda. 


\section{Conclusión}

La adivinanza por todo lo que hemos visto ha sido, es y seguirá siendo parte de nuestro acervo tradicional. En ella se da un código lúdico-poético, gratamente asimilado y transmitido a través de las generaciones y culturas, sin menoscabo de su pervivencia, enriquecimiento y valor. El juego ingenioso que se oculta en las adivinanzas contribuye a desarrollar la imaginación y la capacidad de comunicación de quien lo practica, además de incrementar su acervo léxico y su sensibilidad en el manejo del lenguaje y el ritmo, lo que le permite un mejor acercamiento a la poesía.

\section{REFERENCIAS}

Alatorre, Antonio, 1973. "De folklore infantil", en Lírica infantil de México, Artes de México 162, 35-46.

Álvarez, Rosanela, 2001. La quisicosa. Adivinanzas tradicionales para niños, México, CIDCLI.

AмIтн, Jonathan D., 1997. "Tan ancha como tu abuela", Tlalocan $12,141-219$.

Bermejo Meléndez, Belén, 2000. Las mejores adivinanzas, Madrid, El Ateneo.

Beutler, Gisela, 1979. Adivinanzas españolas de la tradición popular actual de México, principalmente de las regiones de Puebla-Tlaxcala, Wiesbaden, Franz Steiner Verlag GMBH.

Cerrillo, Pedro C., 2000. Adivinanzas populares españolas (Estudio y antología), Castilla-La Mancha, Ediciones de la Universidad.

—, 1989. "Lírica popular de tradición infantil", en Sobre didáctica de la lengua y la literatura Homenaje a Arturo Medina, Madrid, Escuela Universitaria "Pablo Montesino", pp. 465-472.

- y Jaime GARCía PADRINo (coord.), 1992. Literatura infantil y enseñanza de la literatura, Castilla-La Mancha, Ediciones de la Universidad. 
Etхаве, Regino, 2004. Adivinancero, $1^{\mathrm{a}}$ ed., ilus. Mikel Valverde, Madrid, Hiperión.

FARfán, Rosa María y Mario Calderón, 1993. La adivinanza, Puebla, Cajica.

Gárfer, José Luis y Concha Fernández, 1994. Adivinancero antológico español, Madrid, Ediciones del Prado.

—, 1983. Adivinancero popular español I, Madrid, Taurus.

—, 1993. Adivinancero temático español. Vegetales, Madrid, Taurus.

GonzÁlez Gutiérrez, María Gabriela, 1999. Hacer visible lo invisible. Estructuras y funciones de la adivinanza mexicana tradicional, México, Benemérita Universidad de Puebla- Plaza y Valdés Editores.

Johansson, Patrick, 2004. Zazanil. La palabra-enigma. Acertijos y adivinanzas de los antiguos nahuas, México, Mc Graw Hill.

Miaja de la Peña, María Teresa, 1992. "Adivina, adivinanza... en la tradición popular mexicana", en Memoria de Nuevo Mundo. Castilla-La Mancha y América en el Quinto Centenario (coord. Pedro Ibáñez), Madrid, Ediciones de la Universidad Castilla-La Mancha, pp. 223-234.

—, 1997. "La adivinanza en la tradición folklórica mexicana", en Varia lingüística y literaria, 50 años del CELL, vol. III (Literatura siglos XIX y XX), México, El Colegio de México, pp.133-147.

Rincón, Valentín y Cuca Serratos, 2003. Adivinancero, ilus. Alejandro Magallanes, México, Conaculta.

Rodríguez Rivera, Virginia, 1943. "Adivinanzas en México", Revista Hispánica Moderna 9, 269-276.

Sahagún, Bernardino de, 2000. Historia general de las cosas de Nueva España, 3 tomos, México, Conaculta (Cien de México).

SAlgado, Antonio, 1998. Adivina, adivinador. Las mejores adivinanzas en acróstico, México, SELECTOR.

—, 1988. Agua pasa por mi casa...cate de mi corazón. El libro de oro de las adivinanzas, México, SELECTOR.

—, 1990. Lana sube, lana baja. Las mejores adivinanzas modernas de México, México, SELECTOR. 